\title{
Mental health following terrorist attacks
}

\author{
MATTHEW G. WHALLEY and CHRIS R. BREWIN
}

\begin{abstract}
Summary We review the current literature relating to mental health following terrorist attacks. Studies assessing symptoms of stress in the general population and those assessing the mental health of direct victims are considered. Use of mental health services following an attack is reviewed and recommendations are offered.
\end{abstract}

\section{Declaration of interest None.}

Terrorist activity in the UK reached a peak during the 30 years from the late 1960s to the late 1990s, with hundreds of incidents associated with the political conflict in Northern Ireland. Although terrorist attacks have occurred all over the world, they have been particularly numerous in France, India, Iraq, Israel, Russia, Spain, Sri Lanka and the UK. More recently, Islamic terrorist groups have targeted London, Madrid and New York City, as well as numerous other cities in Europe, Asia and North America. Although the psychiatric impact of terrorist violence has been repeatedly noted, it is only comparatively recently that there has been systematic research into its effects on victims and on the wider community. This evidence now permits some estimate to be made of the mental health consequences of terrorism and of the challenge for psychiatric services.

\section{MENTAL HEALTH OF THE GENER AL POPULATION}

Studies conducted in representative samples of the general population following terrorist events can be divided into those that have investigated the prevalence of 'substantial stress' (the presence of a predetermined level of psychological symptoms) and those that have attempted to estimate the prevalence of diagnosable psychiatric disorders. Catchment areas studied vary from city districts, cities, and surrounding regions, to whole countries. Within the first month after the 11 September 2001 attacks, symptoms of stress were evident in individuals geographically far distant from the original incident, and nationally depressive symptoms in the USA rose for 4 weeks only to fall back to previous levels thereafter (Knudsen et al, 2005).

Schuster et al (2001) demonstrated that the proportion of people experiencing substantial stress was negatively associated with distance from the attacks of 11 September. Therefore, for comparison purposes it is easiest to consider studies that have sampled from the city where the incident happened or from the surrounding area (details of these studies are presented as a data supplement to the online version of this editorial). Despite using a variety of different instruments, these studies reveal a close relationship between the time postincident and the prevalence of 'substantial stress'. Rates are extremely high in the first few days after the incident but are already in decline in the first 2 weeks and by 6-8 weeks have fallen by two-thirds. Thus for the majority of individuals significant stress symptoms are temporary and are unlikely to have lasting mental health implications (Vázquez et al, 2006). However, a significant minority will continue to have symptoms. Over 6 months after the 11 September attacks, $5.3 \%$ of New York City residents continued to meet criteria for subsyndromal post-traumatic stress disorder (Galea et al, 2003), a condition associated with substantial functional impairment.

The data on rates of probable acute stress disorder or post-traumatic stress disorder (PTSD) show a similar pattern. Rates of PTSD in the general population attributable to single attacks may be as high as $11-13 \%$ in the first 6 weeks but decline sharply with time, with most studies indicating rates below 3\% 2 months after the incident.
When considering these studies it is important to bear in mind that stress symptoms measured in the immediate aftermath of an attack are not necessarily 'post-traumatic'. One of the hallmarks of PTSD is a sense of extreme threat that endures despite the danger having passed, something that can rarely be assumed about a terrorist attack. Thus, symptom reporting following the Madrid train bombings was particularly high in regular train passengers (Vázquez et al, 2006). Transient symptoms should in most cases therefore be regarded as a general and not necessarily inappropriate stress response, partly reflecting involvement and concern with one's own safety as well as with the safety of the community, family and friends. Symptom reporting will also be associated with actual losses of people, possessions and employment (Galea $e t$ al, 2002; DeLisi et al, 2003).

It should also be remembered that community samples will contain a proportion of people who may have particular reasons to feel threatened by the events. The data suggest that those reporting more symptoms will include members of minority groups (Schuster et al, 2001; Galea et al, 2002; Rubin et al, 2005), people with previous experience of adversity (Galea $e t$ al, 2002, 2003) and people who have developed psychiatric disorders in response to past stresses (DeLisi et al, 2003). For these groups the typically intense levels of media coverage and general concern around terrorist attacks may increase general levels of stress by acting as a potent reminder of feared outcomes or of thematically similar experiences from the past. More research is needed into the long-term outcomes for these at-risk groups.

\section{Children}

There are fewer studies of children's responses to terrorism. Henry et al (2004) found no significant difference from parental reports in general levels of anxiety and depression in children from Chicago in the 100 days before and after the 11 September attacks. A number of studies have explicitly assessed children's reactions to terrorist events. Close to 1 year after the bombing of the Alfred P. Murrah Federal Building in Oklahoma City, about $5 \%$ of elementary schoolchildren reported clinically significant levels of symptoms of PTSD (Gurwitch et al, 2002). A year later, almost $20 \%$ of middle schoolchildren living 100 miles from the city reported current bomb-related 
symptoms that impaired their functioning at home or at school (Pfefferbaum et al, 2000).

Four days after 11 September 2001, $35 \%$ of a national sample of American parents reported that their child had at least one of five stress symptoms (Schuster et al, 2001). Six weeks later more than $60 \%$ of parents in the New York City metropoli$\tan$ area reported that their child was upset (Schlenger et al, 2002) or had moderate post-traumatic stress reactions (Fairbrother et al, 2003). Without more normative data it is difficult to assess the significance of these reports. However, two studies have carried out diagnostic assessments in community samples of children after 11 September. One month later, $8 \%$ of Seattle children were estimated to have diagnosable levels of PTSD symptoms (Lengua et al, 2005). In New York City itself, 6 months later Hoven et al (2005) reported that $28.6 \%$ of children had at least one probable anxiety/depressive disorder, the most common being agoraphobia (14.8\%), separation anxiety $(12.3 \%)$ and PTSD (10.6\%).

\section{MENTAL HEALTH OF DIRECT VICTIMS}

Another group of studies have reported on the mental health of people with direct experience of a terrorist attack, typically using diagnostic interviews or screening tools designed to estimate the prevalence of disorder. In these studies PTSD appears to be the most common disorder attributable to the attack, followed by depression (North et al, 1999; Miguel-Tobal et al, 2005), although other sequelae include traumatic grief, panic, phobias, generalised anxiety disorder and substance misuse (prevalence rates of PTSD in direct victims of a number of major terrorist attacks are presented in the data supplement to the online version of this editorial). Direct victims of terrorist attacks are those most affected, usually by being physically present at the attack site or by having a close family member killed or injured. Despite wide variations in the number killed in the attacks and the timing of assessments, there is remarkable uniformity that within 2 years of the incident $30-40 \%$ of the people closest to the site of the attack are likely to develop a clinically diagnosable disorder. Few data are available for longer-term outcomes, but even $2 \frac{1}{2}$ years after the Paris attacks the rate of PTSD among direct victims was $25 \%$, and 2 years after the Pentagon attack on 11 September over $20 \%$ of employees who were present and responded to the survey were found to have PTSD. These figures emphasise that many reactions are intense and long-lasting and cannot be dismissed as normal, transient responses to traumatic events.

Studies of emergency workers have usually found considerably lower levels of psychopathology than in direct victims. Retrospective reports by body handlers describing their reactions at the time of the Oklahoma City bombing and 1 year later indicated negligible levels of PTSD and depression (Tucker et al, 2002), and North et al (2002) reported a PTSD rate of $13 \%$ among firefighters 3 years after the bombing. Two months after the Madrid bombings Miguel-Tobal et al (2005) found a rate of $1.2 \%$ for PTSD and $2 \%$ for depression among emergency personnel. Six months after the 11 September attack on the World Trade Center, $14.3 \%$ of those involved in the rescue effort in New York City had probable PTSD (Galea et al, 2003), but there appeared to be only a small excess of PTSD symptoms in handlers working in canine search and rescue teams who were deployed following 11 September, compared with non-deployed controls (Alvarez \& Hunt, 2005).

Studies of emergency workers are hard to compare because response rates varied, and in all of them there was considerable scope for response biases to operate. Although it is not likely that these groups will respond with high levels of disorder, it is important to consider that actual levels of exposure to the attack site, and to scenes of severe injury and grotesque death, are likely to vary enormously, even among individuals attending the same incident. For example, in a study of firefighters who worked in the aftermath of the 1995 Oklahoma bombing, North et al (2002) found that time working on the site and time spent in the 'pit', a particularly perilous area of the building, were associated with increased PTSD prevalence. The involvement of trauma and occupational health advisors may be of great importance in ensuring that organisations recognise the potentially toxic effects of high or prolonged levels of exposure and provide appropriate levels of protection and support.

\section{Children}

Again there have been fewer systematic studies of child victims. Elbedour et al (1999) found that $50 \%$ of the daughters and $23.1 \%$ of the sons of those killed in the Hebron massacre were suffering from probable PTSD. Children were more likely to experience post-traumatic symptoms following the Oklahoma City bombing if they had been bereaved (Pfefferbaum et al, 1999). Other commentators have drawn attention to a significant risk of psychological disorder in children who are direct victims, suffer bereavement or other losses, or have to witness repeated reminders of the attacks, including parental distress (Fairbrother et al, 2003; Hoven et al, 2005). Distress and disorder may manifest themselves in different ways depending on the child's developmental stage, and it is likely that children's distress is systematically underestimated by adults (Gurwitch et al, 2002; Koplewicz et al, 2004).

\section{RECEIPT OF MENTAL HEALTH SERVICES}

There is now a substantial evidence base indicating that PTSD can be successfully treated. Six months after the Oklahoma City bombing $69 \%$ of survivors had received some form of mental health intervention, although this might only have consisted of psychological debriefing (North et al, 1999). Similarly, $74 \%$ of survivors of the Paris bombings with PTSD received psychological treatment after the attack (Verger et al, 2004). In contrast, receipt of services in the wider population appears to be considerably lower. Three to six months after 11 September only about a quarter of those with the most severe PTSD symptoms in New York City were receiving counselling or mental health treatment (DeLisi et al, 2003). By 6-9 months after 11 September about a third of New York City residents with probable PTSD or depression had sought help from professionals, and these overwhelmingly consisted of people who had previously received mental health services (Stuber et al, 2006). Virtually nothing is known about the proportion of survivors of terrorist events with PTSD or other disorders who received appropriate, evidence-based treatment for their conditions, or how successful these interventions were at ameliorating their symptoms.

\section{CONCLUSIONS}

Terrorist attacks have widespread mental health effects, even on communities geographically distant from the attacks. In the 
main these effects will be short-lived but there is a minority of individuals not directly involved in the incidents who will continue to experience clinical or subclinical levels of symptoms, often accompanied by functional impairment. Consistent with data on exposure and risk, $30-40 \%$ of people directly affected by terrorist action are likely to develop PTSD, and at least $20 \%$ are likely still to be experiencing symptoms 2 years later. Less is known about the mental health impact on children, but this too appears to be considerable (see the data supplement to the online version of this editorial). In contrast, there is less evidence that rescue workers and members of the emergency services are at high risk of developing disorder.

These findings have important implications for health services. Whereas some direct victims are likely to be in contact with providers of psychological services, in New York City following 11 September only around a quarter to a third of adults and children with significant post-traumatic stress symptoms received any treatment at all. Survivors with no previous contact with services were least likely to benefit from what was available. This was despite the strenuous efforts of those involved in Project Liberty, an unprecedented exercise involving over 100 mental health agencies delivering free public education and crisis counselling. If this level of unmet need is replicated elsewhere, it suggests that a targeted, active outreach programme will need to be a major feature of the response, for example using a 'screen and treat' approach. An important future task is to demonstrate that an outreach programme can be effective in identifying individuals with significant symptoms or functional impairment, in facilitating access to evidencebased treatment and in achieving the kind of positive health outcomes typically obtained in treatment trials for PTSD.

\section{ACKNOWLEDGEMENTS}

We thank Marylene Cloitre, Sandro Galea and Guinevere Tufnell for advice and comments.

MATTHEW G.WHALLEY, PhD, CHRIS R. BREWIN, PhD, Sub-Department of Clinical Health Psychology, University College London, UK

Correspondence: Dr Matthew G.Whalley, Sub-Department of Clinical Health Psychology, University College London, Gower Street, London WCIE 6BT, UK. Email: m.whalley@ucl.ac.uk

(First received I2 May 2006, final revision 23 August 2006, accepted I September 2006)

\section{REFERENCES}

Alvarez, J. \& Hunt, M. (2005) Risk and resilience in canine search and rescue handlers after 9/1I. Journal of Traumatic Stress, 18, 497-505.

DeLisi, L. E., Maurizio, A., Yost, M., et al (2003) A survey of New Yorkers after the September II, 200I, terrorist attacks. American Journal of Psychiatry, 160 , 780-783.

Fairbrother, G., Stuber, J., Galea, S., et al (2003) Posttraumatic stress reactions in New York City children after the September II, 200I, terrorist attacks. Ambulatory Pediatrics, 3, 304-311.

Galea, S., Ahern, J., Resnick, H., et al (2002) Psychological sequelae of the September II terrorist attacks in the New York city. New England Journal of Medicine, 346, 982-987.

Galea, S., Vlahov, D., Resnick, H., et al (2003) Trends of probable post-traumatic stress disorder in New York City after the September II terrorist attacks. American Journal of Epidemiology, 158, 514-524.

Gurwitch, R. H., Sitterle, K. S., Young, B. H., et al (2002) The aftermath of terrorism. In Helping Children Cope with Disasters: Integrating Research and Practice (eds A. M. La Greca \& W. K. Silverman), pp. 327-357. American Psychological Association.

Henry, D. B., Tolan, P. H. \& Gorman-Smith, D (2004) Have there been lasting effects associated with the September II, 200I, terrorist attacks among innercity parents and children? Journal of Professional Psychology: Research and Practice, 35, 542-547.

Hoven, C. W., Duarte, C. S., Lucas, C. P., et al (2005) Psychopathology among New York City public school children 6 months after September II. Archives of General Psychiatry, 62, 545-552.

Knudsen, H. K., Roman, P. M., Johnson, J. A., et al (2005) A changed America? The effects of September Ilth on depressive symptoms and alcohol consumption. Journal of Health and Social Behaviour, 46, 260-273.

Koplewicz, H. S., Cloitre, M., Reyes, K., et al (2004) The 9/1I experience: who's listening to the children? Psychiatric Clinics of North America, 27, 491.

Lengua, L. J., Long, A. C., Smith, K. I., et al (2005) Pre-attack symptomatology and temperament as predictors of children's responses to the September II terrorist attacks. Journal of Child Psychology and Psychiatry, 46, 631-645.

Miguel-Tobal, J. J., Cano-Vindel, A., Iruarrizaga, I. et al (2005) Psychopathological repercussions of the
March II terrorist attacks in Madrid. Psychology in Spain, 9, 75-80.

North, C. S., Nixon, S. J., Shariat, S., et al (1999)

Psychiatric disorders among survivors of the Oklahoma City bombing. JAMA, 282, 755-762

North, C. S., Tivis, L., McMillen, J. C., et al (2002) Coping, functioning, and adjustment of rescue workers after the Oklahoma City bombing. Journal of Traumatic Stress, 15, |7|-|75.

Pfefferbaum, B., Nixon, S. J., Krug, R. S., et al (1999) Clinical needs assessment of middle and high school students following the 1995 Oklahoma City bombing. American Journal of Psychiatry, I56, 1069-1074.

Pfefferbaum, B., Seale, T. W., McDonald, N. B., et al (2000) Posttraumatic stress two years after the Oklahoma City bombing in youths geographically distant from the explosion. Psychiatry, 63, 358-370.

Rubin, G. J., Brewin, C. R., Greenberg, N., et al (2005) Psychological and behavioural reactions to the bombings in London on 7 July 2005: cross sectional survey of a representative sample of Londoners. BMJ, 331, 606

Schuster, M. A., Stein, B. D., Jaycox, L. H., et al (200I) A national survey of stress reactions after the September II, 200I, terrorist attacks. New England Journal of Medicine, 345, I507-1512.

Stuber, J., Galea, S., Boscarino, J. A., et al (2006) Was there unmet mental health need after the September II, 200I, terrorist attacks? Social Psychiatry and Psychiatric Epidemiology, 4I, 230-240.

Tucker, P. M., Pfefferbaum, B., Doughty, D. E., et al (2002) Body handlers after terrorism in Oklahoma City: predictors of posttraumatic stress and other symptoms. American Journal of Orthopsychiatry, 72, 469-475.

Vázquez, C., Pérez-Sales, P. \& Matt, G. (2006) Posttraumatic stress reactions following the March II, 2004 terrorist attacks in a Madrid community sample: a cautionary note about the measurement of psychological trauma. Spanish Journal of Psychology, 9, 61-74.

Verger, P., Dab, W., Lamping, D. L., et al (2004) The psychological impact of terrorism: an epidemiologic study of posttraumatic stress disorder and associated factors in victims of the 1995-1996 bombings in France. American Journal of Psychiatry, I6I, 1384-1389. 